\title{
Construction of Alcohol Level and Temperature Monitoring Device
}

\author{
Morakinyo R.O ${ }^{1}$.,Usikalu M.R ${ }^{1 *}$, Emetere M. $\mathbf{E}^{1,2}$, Ayanbisi O. $\mathbf{O}^{1}$ \\ ${ }^{1}$ Department of Physics, Covenant University, Ota, Ogun State, Nigeria \\ ${ }^{2}$ Department of Mechanical Engineering, University of Johannesburg, South Africa \\ morakinyoruth@gmail.com ${ }^{1}$; moji.usikalu@ covenantuniversity.edu.ng*; \\ moses.emetere@ covenantuniversity.edu.ng ${ }^{1,2}$;olusegun.ayanbisi@ covenantuniversity.edu.ng ${ }^{1}$
}

\begin{abstract}
This study proposed a suitable method to measure exposure to alcoholic content in commonly consumed plant and fruit drinks such as Lemon, Ginger, Garlic, Zobo, and Omi-ogi (extracted liquid after sieving of grounded corn).A prototype of alcohol detection and temperature monitoring device was constructed using Arduino mega microcontroller coupled with MQ-3 as alcohol sensor, LM35 as temperature sensor with LCD display screen.LM35 microcontroller temperature sensoron the device was used to measure the room temperature in order to compare valuesobtained with that of liquid in glass thermometer measurement.The mean temperature measured is $28.7{ }^{\circ} \mathrm{C}$ and $29.3{ }^{\circ} \mathrm{C}$ from the constructed device and the conventional thermometer respectively with accuracy of $97.9 \%$ compared with conventional thermometer. MQ-3 alcohol sensor was used to measure and compare the alcoholic content in commonly consumed alcoholic drinks and plant/ fruit drinks. The result showed that the alcoholic content in plant and fruit drinks increases due to fermentation process in the natural drinks. Theresults of the experiment show that the alcohol sensor has a fast response time of 1 second.
\end{abstract}

Keywords: Alcohol level, Temperature sensor, Ardiuno, Alcoholic drinks, Plant drinks

\section{INTRODUCTION}

Human being is exposed to a level of alcoholic intakes in their day to day consumption of extraction from some plant and fruits drinks as food, to prevent disease or treating an ailment. Many of the commonly consumed fruits and drinks contain some level of alcohol when allowed to ferment. An alcoholic drink is a drink that contains the recreational drug ethanol made from the fermentation of grains, fruits or other sources of sugar [1]. Alcoholic drinks account for about 3 million deaths, 200 diseases and injury, and $5.1 \%$ global burden of disease every year [2]. The chronic alcohol intake can damage the liver thereby preventing it from proper removal of harmful substances from the body. It can prevent the body of the consumer from fighting viruses and bacteria which make such person vulnerable to illnesses such as tuberculosis and pneumonia [2,3].

Ethanol used in the production of alcohol has its source from commonly consumed fruits and grains. The concentration of ethanol in all these fruits and grains needs to be determining to avoid exposure to the ethanol above the limit that is detrimental to human health. Breathalyser is an instrument for measuring blood alcohol content in a breath sample. Public breathalyser is used by consumer to test source of alcohol in food.Semiconductor gas sensors operate on the principle that the conductance of a tin oxide layer increases in the presence of a reducing gas such as vaporized ethanol. There are various types of breathalyser among which are semiconductor breathalyser, fuel cell breathalyserand spectrometer breathalyser [4, 5. 6]. Semiconductor breathalyser uses semiconductor sensor to measure the degree of oxidation of alcohol in person's breath. It has low power consumption and it is cost effective. It is very efficient for personal use. Fuel cell breathalyser is majorly use by police, it is very sensitive and gives accurate, reliable result. The sensor's uses an electrochemical process that generates current as a result of oxidation of alcohol content in the breath sample. Spectrometer breathalyser is very bulky and expensive. It is usually set up at the police station. It gives exact and precise reading. Spectrometer breathalyser uses infrared sensors which produces changes in the wavelength and energy when exposes to alcoholic vapour.Many researchers in nineteen century havestudied the possibility of using breath to test alcohol in a person breath. A test for alcohol in a person's breath was developed from the grand work done by Francis Edmund between 1833 and 1874[7].Therefore, the aim of this study is to construct and implement a suitable alcohol level 
monitoring device to measure exposure to alcoholic content in commonly consumed alcoholic and natural fruit drinks.

\section{MATERIALS AND METHODS}

The materials used for the study are as follows:

- Arduino mega 2560

- MQ-3 alcohol sensor

- LM35 temperature sensor

- $16 \times 2$ LCD (Liquid Crystal Display)

- Alcoholic samples ( Orijin,Confam, Chelsea, Action Bitter,Derok)

- Natural plants and fruit drinks samples( Garlic, Lemon , Hibiscus flower, Ginger, Omi Ogi)

Alcoholic drinks sample (Orijin, Confam, Chelsea, Action Bitter, and Derok) were purchase in the local market and emptied inside a bottle. Natural plant and fruit drinks were equally purchased. Garlic, ginger, hibiscus flower, were blend, lemon juice squeezed and extract water from corn were put inside a labelled plastic. The block diagram of the proposed system consist of power supply section, MQ-3 alcohol sensor, LCD and the Arduino microcontroller as shown in Figures 1.

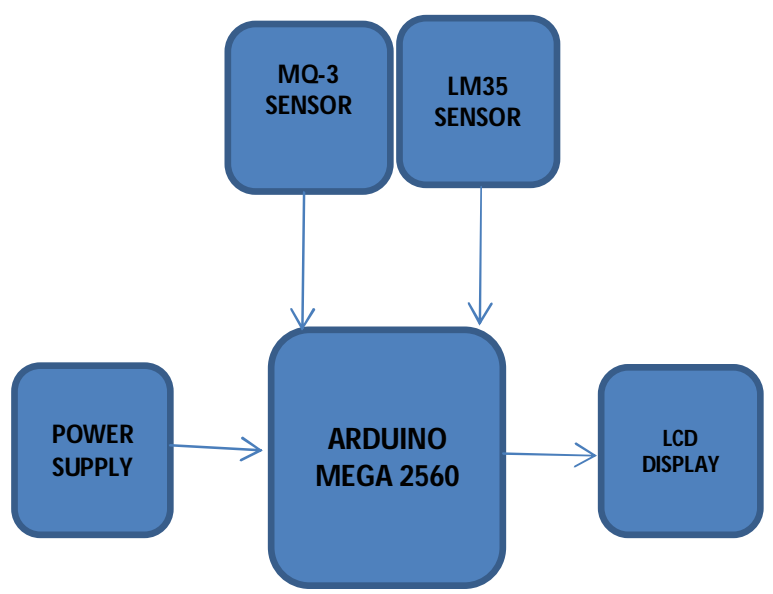

Figure 1: Block diagram of the system

The proposed design is made up of several components that made up the whole system. MQ-3 is the alcohol detection unit, LM35 is the temperature sensor, and the LCD is used to display the alcohol and the temperature value. The ATmega328 microcontroller is used to get the output from the alcohol and the temperature sensor. The Arduino Mega 2560 provides environment for programming, to write the code, compile, generate hex file and load it to the microcontroller[8, 9, 10].
The MQ-3 sensor is made of tin dioxide $\left(\mathrm{SnO}_{2}\right)$ which is very sensitive to alcohol and less sensitive to Benzene. It has a simple drive circuit with fast response, stability, and long life. On the sensor, port pins 1, 2 and 3 represents the output, GND and VCC respectively (Figure 2). The sensor detects the presence of alcohol gas in the air, the sensor can work at temperatures range from -10 to $50^{\circ} \mathrm{C}$ with a power supply between $150 \mathrm{mV}$ to $5 \mathrm{~V}$. The sensing range is from $50 \mathrm{ppm}$ to $500 \mathrm{ppm}$, which is suitable for breathalysers. The sensor has a wide detecting range with fast response and highly sensitive[11]. It operates with voltage of $+5 \mathrm{~V}$ and can be used to detect $\mathrm{NH}_{3}, \mathrm{NO}_{\mathrm{X}}$, Alcohol, Benzene, Smoke etc. It can operate as a digital or analog sensor.

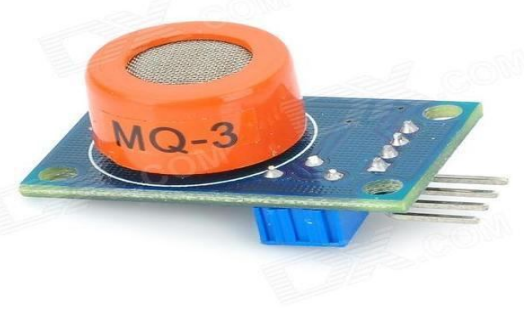

Figure 2: MQ-3 Alcohol Sensor[11]

LM35 is a temperature sensor with an output signal that is proportional to the temperature[12].The output voltage gives a temperature reading in Celsius. It can take measurement from $-55^{\circ} \mathrm{C}$ to $150^{\circ} \mathrm{C}$. It gives an accurate measurement at optimal temperature and humidity [11]. The output voltage can readily be converted to centigrade.LM35 sensor has a linear scale with0.5 accuracy at $25^{\circ} \mathrm{C}$, it operates at the voltage between $4 \mathrm{~V}$ to $30 \mathrm{~V}$ and has low impedance output. Figure 3 is the picture of LM35 temperature sensor.

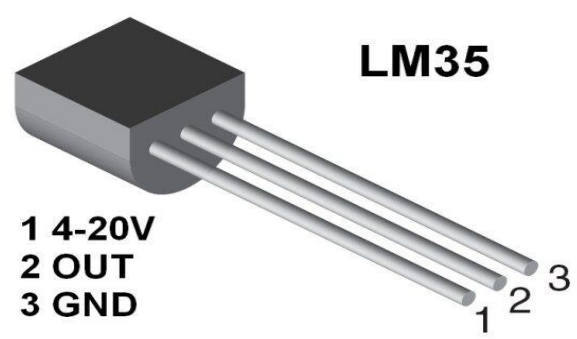

Figure 3: LM35 Temperature Sensor

The Arduino Mega 2560 is known as microcontroller board which is based on the ATmega2560 (Figure 4). It consist of 54 digital input/output pins, 16 analog inputs, 4 UARTs (hardware serial ports), a $16 \mathrm{MHz}$ 
crystal oscillator, a USB connection, a power jack, an ICSP header, and a reset button[1316]. It has been updated to Arduino Mega. It is employed to take the output reading from the alcohol and the temperature sensor by programming it on the Arduino IDE. The arduino IDE was used to programme the arduino mega 2560. The software is a program that manipulates input data from the sensor of Alcohol and indicates it on the unit of, DC motor, alarm unit and LCD display. The code of the program was written on Arduino sketch and sent to ATMEGA328 program memory of microcontroller with the use of development board in Arduino Uno. The Arduino sketch IDE was used to generate the hex file. The Arduino Integrated Development Environment (IDE) is an application written as functions from $\mathrm{C}$ and $\mathrm{C}++($ arduino.cc). It is used in writing and uploading programs to Arduino compatible boards in conjunction with the third-party cores and other vendor development boards.
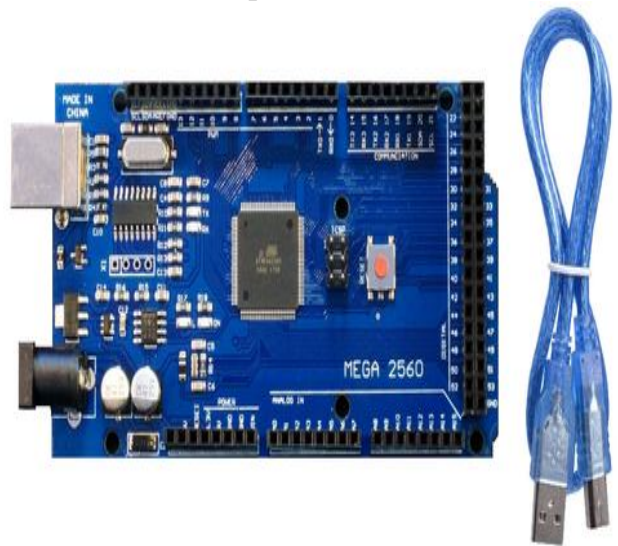

Figure 4: Arduino Mega 2560

The LCD display is an electronic display module that uses liquid crystal to produce a visible image. It usually displays 16 characters in 2 rows. The LCD is used in this study to display the alcohol content from the MQ3 sensor and the temperature reading from the LM35 sensor.The constructed device is shown in Figure 5.

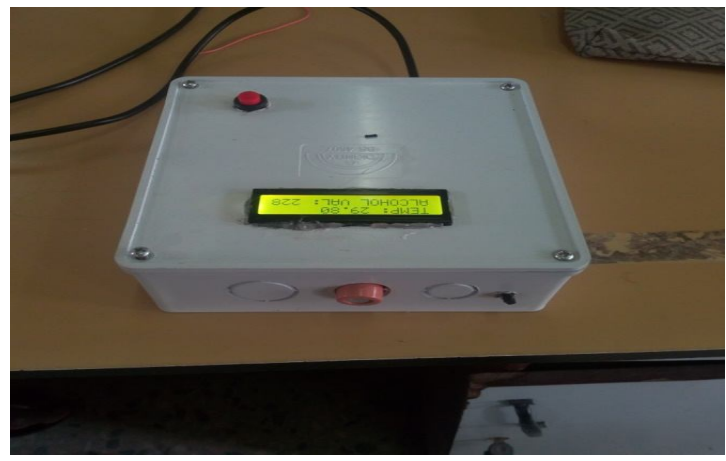

Figure 5: Alcohol Level and Temperature Monitoring Device

\section{RESULTS AND DISCUSSION}

The alcohol sensor of the constructed device has a fast response time of 1 second which was constant throughout the experiment. The accuracy of the LM35 sensor was 97.9\%. The constructed device was used to measure the alcohol level of ten samples; consisting of five commonly consumed alcoholic drinks: Action bitter,Confam,Chelsea, Derok, Orijin available in the local area and five extracts from commonly consumed natural plant and fruit drinks: Ginger, Garlic, Lemon, Zobo, Omi-ogi. Fifty (50) g of each sample was put inside a plastic bottle each weighing $25 \mathrm{~g}$. Reading were taken for ten days with the MQ-3 Arduino module sensor connected to the computer to take measurement for 1 minute, at an average of a reading per second and the mean reported. Figure 6 displayed the mean temperature measured from this device and conventional thermometer. The mean temperature measured from LM35 was $28.7^{\circ} \mathrm{C}$ while $29.3^{\circ} \mathrm{C}$ was obtained mean measured with conventional thermometer which suggest that the constructed device is working properly with good accuracy. The room temperature was taken for ten days using the liquid in glass thermometer and LM35 temperature sensor. Figure7 displayed the mean alcohol level of each sample over the period of ten days. The alcohol level of the alcoholic drinks on day 1 was higher than those measured from natural drinks. The resultsof alcohol level in each sample werepresented in Table 1. The result shows that the level of alcohol increases in most of the natural plant and fruit drinks, while the level of alcohol decreases in most of the alcoholic drink from day 1-10. This is due to the fact that the fermentation processes have been completed in the alcoholic drink which is still on going with the natural plant and fruit drinks. Also, the level of alcohol increases significantly in garlic due to fermentation with increase in days. Garlic is a plant in onion family that grows in many part of the world and had been used for its health and medicinal purposes. Garlic is very nutritious and contains essential elements such as manganese, calcium, potassium, phosphorous, iron, and vitamins.It is used in preventing and treatment of some diseases such as common cold, flu, blood pressure. It is an anti-oxidant, it improve cholesterol level and bone health. It was observed that a regular intake of garlic may serve as a chemo-preventive agent for lung cancer [17]. Further research had revealed that too much consumption of garlic can result in head ache, inattention and distraction [18]. 


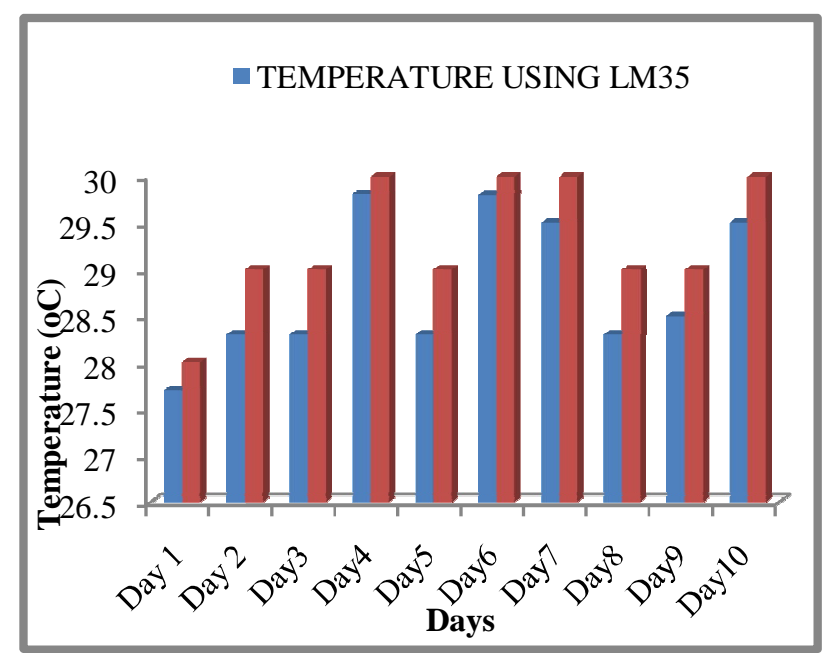

Figure 6: LM35 Sensor and Conventional Thermometer Measurement

Table 1: Alcohol Level of each Sample

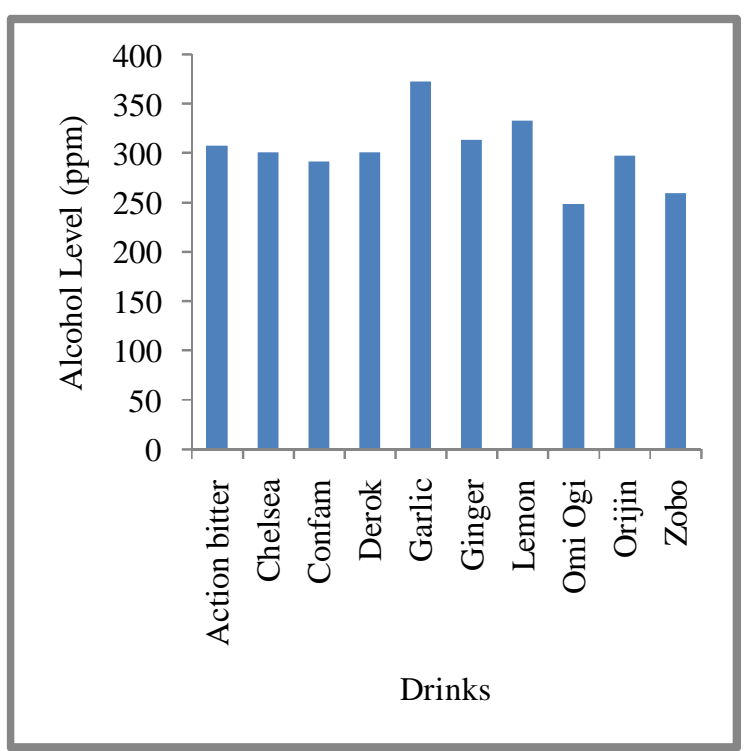

Figure 7: Mean Alcoholic Level in Drinks

\begin{tabular}{|c|c|c|c|c|c|c|c|c|c|c|c|}
\hline Samples & Day1 & Day2 & Day3 & Day4 & $\begin{array}{l}\text { Day5 } \\
\end{array}$ & Day6 & Day7 & $\begin{array}{l}\text { Day8 } \\
\end{array}$ & Day9 & Day10 & Mean \\
\hline Action bitter & 334.5 & 310.5 & 297.7 & 333.8 & 302.0 & 308.5 & 291.2 & 302.8 & 280.8 & 312.6 & 307.5 \\
\hline Chelsea & 346.9 & 334.7 & 283.1 & 328.6 & 304.9 & 294.1 & 301.1 & 274.8 & 272.4 & 265.8 & 300.6 \\
\hline Confam & 320.1 & 293.7 & 270.1 & 333.6 & 304.4 & 291.9 & 281.1 & 292.7 & 261.5 & 270.1 & 291.9 \\
\hline Derok & 335.2 & 317.8 & 271.9 & 321.4 & 314.9 & 291.9 & 318.9 & 278.6 & 282.2 & 274.4 & 300.7 \\
\hline Garlic & 295.8 & 316.5 & 346.3 & 365.8 & 369.8 & 368.2 & 378.2 & 425.0 & 436.1 & 425.2 & 372.7 \\
\hline Ginger & 315.2 & 295.6 & 314.5 & 326.8 & 364.6 & 290.0 & 296.8 & 333.5 & 323.8 & 283.1 & 313.0 \\
\hline Lemon & 341.4 & 265.5 & 307.5 & 350.3 & 361.0 & 360.2 & 358.4 & 336.9 & 345.0 & 305.8 & 333.2 \\
\hline Omi Ogi & 254.1 & 265.5 & 243.2 & 239.2 & 246.4 & 252.0 & 259.3 & 257.4 & 227.7 & 232.7 & 247.8 \\
\hline Orijin & 325.7 & 265.5 & 270.1 & 329.1 & 308.3 & 323.9 & 318.9 & 288.8 & 279.2 & 266.8 & 297.6 \\
\hline Zobo & 200.7 & 221.6 & 263.6 & 289.7 & 279.4 & 246.3 & 284.6 & 283.7 & 279.3 & 246.7 & 259.6 \\
\hline
\end{tabular}




\section{CONCLUSION}

MQ-3 sensor was used to construct alcohol level device which was used to determine the alcoholic 9 . content in some commonly consumed alcoholic drinks, plant and fruit drinks. From the research, alcoholic content of most plant and fruit drinks increases with days.Most of the commonly consumed plant and fruit drinks contained some level of alcohol when allow to ferment for days. This study shows that garlic and lemon when soaked for days contains level of alcohol that is comparable with the alcoholic drink. The fermented garlic and lemon required further research to prevent excessive intake of alcohol.

\section{ACKNOWLEDGEMENT}

Authors acknowledged the support of Covenant University for the publication of the study

\section{REFERENCES}

1. Belitz, H.D., Grosch, W., and Schieberle, P. (2009). Alcoholic beverages.

https://www.researchgate.net/publication/227191780,

DOI: 10.1007/978-3-540-69934-7_21

2. World Health Organization (WHO, 2018) Factsheets on the effects of alcohol, https://www.who.int/news-room/fact-

sheets/detail/alcohol

3. Aweda M. A, Usikalu M. R.,Ding N, Wan J. H, Zhu J (2010). Genetoxic effects of $2.45 \mathrm{GHz}$ microwave exposure on different cells of Sprague Dawley rats International Journal Genetics and Molecular Biology2(9): 189-197

4. Barba-Maza, L. M., and Sanchez-Lopez, C. (2016). Development of a breathalyser for car drivers. IEEE Int'l Conference on power, electronics and computing DOI: 10.1109/ROPEC 2016.7830528

5. Sorbello, J. G., Devilly, G. J., Allen, C., Hughes, Lee R. J. and Brown, K. (2018). Fuel-cell breathalyser use for field research on alcohol intoxication: an independent psychometric evaluation. PeerJ6x4418; doi 10.7717/peej.4418

6. Krisher, S., Riley, A. and Metha, K. (2014). Designing breathalyser technology for the developing world: how a single breath can fight the double disease burden. Journal of Medical Engineering and Technology, 38(3), DOI: 10.3109/03091902.2014.890678

7. Nkaj, A., and Vyshka, G. (2013). A historical approach to alcohol abuse. Int'1 Journal of Clinical Toxicology, 1: $52-55$

8. 8. Usikalu M. R, Shittu A. H and Obafemi L. N (2018) Construction of an intelligent and efficient light control system, International Journal of Mechanical and Production Engineering Research and Development (IJMPERD), 8(4): 1057-1066

9. Ayara W. A, Omotosho T. V, Usikalu M. R, Singh M. S and SupartaW. (2017) Development of a solar charged laboratory bench power supply, Journal of Physics: Conference Series, 852(1): 012044

10. 10. Usikalu M. R, Adebesin E. and Obafemi L. N (2019a) Design and construction of backpack mobile charger, ARPN Journal of Engineering and Applied Sciences, 14(21): 3743 - 3746

11. Gas Sensor Module (GSM, 2010). Technical Data for MQ-3 Gas Sensor. http://www.hwsensor.com

12. Shi, J. (2013). Design and implementation of an alcohol meter. Bachelor dissertation submitted toFaculty of Engineering and Sustainable Development, University of Gvle

13. Nwoye C. D., Usikalu M. R., Babarimisa I. O., Achuka J. A and Ayara W. A. (2017) Construction of an automatic power switch using infrared motion sensor, Journal of Informatics and Mathematical Sciences, 9(2): 331-337

14. Usikalu M. R, Isaac E. G, Olawole C. O, Abodunrin T. J and Kayode O. T (2019b) Design and construction of solar powered fabric dryer, International Journal of Mechanical and Production Engineering Research and Development, 9(6): 139-148

15. Aleksander S. Anton K., Tatiana K and Danil D. (2019) Threat Model of IOT systems on the example of open UNB protocol, International Journal of Emerging Trends in Engineering Research, 7(9): 283290

16. Elmer R. M (2019). Energy monitoring system incorporating energy profiling and predictive household movement for energy anomaly detection, International Journal of Emerging Trends in Engineering Research, 7(8): 151-156

17. Rana, S.V., Pal, R., Vaspher, K., Sanjeev, K. S., and Ola, R.P. (2011). Garlic in health and disease. Natural research reviews, 24(1): $60-71$

18. Gebresolama G. and Mebrabto, G. (2013). Medicinal values of garlic: a review. Int'l Journal of Medicine and Medical Sciences, 5(9): 401- 408. 